\title{
La dialéctica trascendental de la relación entre los sexos en J. Lacan 1
}

\section{The Transcendental Dialectic of the Sexual Relation in J. Lacan}

\author{
Emma Ingala GómeZ \\ Universidad Complutense de Madrid
}

Recibido: 25-06-2012

Aceptado: 17-12-2012

\section{Resumen}

Basándonos en la lectura de Eugen Fink según la cual el tratamiento del problema de la totalidad en Kant deja al descubierto que el concepto de totum no es sino un enmascaramiento de la nada, y que en ello consiste la verdadera contribución de su crítica en tanto que dialéctica trascendental, pretendemos mostrar que la teoría de la relación sexual contenida en el Seminario Aún de Lacan -y en general el giro a lo real de su doctrina a partir de los años sesenta- presenta una serie de características que ponen de manifiesto su filiación kantiana. El particular análisis de la lógica de la ilusión de Lacan condensado en sus fórmulas de la sexuación tendría como consecuencia el desenmascaramiento de tres nadas: la imposibilidad de la relación sexual, la inexistencia de La mujer y la ausencia del Otro del Otro.

Palabras clave: Lacan, Kant, Dialéctica trascendental, Totalidad, Sexualidad.

\begin{abstract}
On the basis of Eugen Fink's insistence that the true contribution of Kant's transcendental dialectic is that its treatment of the problem of totality reveals the concept 'totum' to be a masking of the nothing, our aim is to highlight that the theory of sexual relation introduced by Lacan in his Seminar Encore -and in general his turn to the real from the 1960 onwards- presents a group of features that make clear its Kantian affiliation. The particular analysis of the logic of illusion contained in Lacan's formulas of sexuation entail the expo-

\footnotetext{
1 Este trabajo se ha realizado dentro del Proyecto FFI2009-12402 Naturaleza humana y comunidad (II): H. Arendt, K. Polanyi y M. Foucault. Tres recepciones de la Antropología política de Kant en el siglo $X X$.
} 
sure of three nothings: the impossibility of the sexual relation, the non-existence of The woman, and the absence of the Other of the Other.

Keywords: Lacan, Kant, Transcendental Dialectic, Totality, Sexuality.

En la sesión del 27 de mayo de 1964 del Seminario XI. Los cuatro conceptos fundamentales del psicoanálisis, Lacan introduce una cuestión que desarrollará con posterioridad en su Seminario XX. Aún (1972-1973): la cuestión de la sexualidad. En contraste con su discurso de los primeros años cincuenta, Lacan traslada el acento del símbolo a la sexualidad, de la lingüística a las pulsiones y del significante al cuerpo, promoviendo un rebasamiento de las fronteras del lenguaje -rebasamiento que había sido tildado de imposible en esos años iniciales de enseñanza ${ }^{2}$ y la inflexión de su teoría denominada giro a lo real. El problema, desde esta nueva perspectiva, ya no es tanto el de descubrir e inventariar las condiciones -simbólicas- de posibilidad de la experiencia humana, sino el de explicar cómo se articulan el más acá y el más allá del orden simbólico y el de gestionar los trasvases entre lo que está simbólicamente codificado - la realidad-y lo que irrumpe como testimonio de lo imposible -lo real-.

Toda pulsión, recuerda Lacan en 1964, es pulsión parcial; no hay una pulsión completa o total que tenga como correlato un goce también total y absolutamente satisfactorio. Ese goce es, pues, estructuralmente imposible -aunque sea, como las totalizaciones de la metafísica dogmática que Kant critica, pensable-: no hay objeto empírico susceptible de cuadrar con ese goce. El universo de lo humano es incompleto, no-todo, finito; no obstante, su incompletud no remite a un objeto extra-fenoménico y substancial que vendría desde una posición trascendente a completarlo siquiera míticamente, sino a un afuera que es nada, que es vacio, y que con su vacío impugna la trascendencia mejor que ningún otro mecanismo -pues al admitir una excepción al sistema, un afuera del sistema que no es sino vacío, se adopta una postura inmanente mucho más fuerte que si sencillamente se cerrara o blindara el sistema sobre sí mismo, ya que en este caso habría que apelar en último término a un garante último externo, a un primer motor, mientras que en el primer caso se preserva la vacante del primer motor sólo para declararla desierta-. No es que al sistema le falte algo, sino que está constituido en su corazón por la nada.

Como toda pulsión es parcial, no hay ninguna de ellas que represente la totalidad de la tendencia sexual. «La sexualidad se instaura en el campo del sujeto por la vía de la falta»3. Lacan distingue además dos tipos de falta: la primera sería falta simbólica, falta de un Otro o un Nombre-del-Padre que actuase como garante último de las construcciones significantes, y la segunda sería falta real, «anterior» 4 . Pero que la falta sea real no significa que sea

\footnotetext{
2 «Hagan ustedes la prueba: verán que nunca saldrán del mundo del símbolo [...]. Cada vez que estamos en el orden de la palabra, todo lo que instaura en la realidad otra realidad, finalmente sólo adquiere su sentido y su acento en función de este orden mismo» J. Lacan, Le Séminaire, livre I. Les écrits techniques de Freud, Paris, Seuil-Points, 1975, p. 364. Sesión del 16/06/1954.

3 J. Lacan, Le Séminaire, livre XI. Les quatre concepts fondamentaux de la psychanalyse, Paris, Seuil, 1973, p. 186. Sesión del 27/05/1964.

${ }^{4}$ Idem.
} 
en lo real, pues esto es imposible: en lo real no falta nada -sólo puede faltar en lo simbólico, como se ve en el célebre ejemplo del libro extraviado en una biblioteca ${ }^{5}-$. La falta es real, afirma Lacan, «porque se relaciona con algo real» e insoslayable: con la muerte6. Negar esta falta real conduce a creer en el mito de la complementariedad de los sexos, en la posibilidad de un otro que complete definitivamente mi incompletud; negar esta falta es, en fin, negar la muerte. «El mito de Aristófanes pone en imágenes de manera patética y engañosa la persecución del complemento, al formular que es el otro, que es la mitad sexual, lo que el viviente busca en el amor. La experiencia analítica sustituye esta representación mítica del misterio del amor por la búsqueda por parte del sujeto, no del complemento sexual, sino de la parte perdida para siempre de sí mismo, que está constituida por el hecho de que él no es sino un viviente sexuado, y que no es más inmortal» ${ }^{7}$. Es, por ende, una parte perdida que nunca se tuvo y que nunca se perdió - un vacío sin pérdida que sin embargo nos constituyelo que el análisis busca.

El Seminario $X X$ vuelve sobre la cuestión de la sexualidad, y nuestra lectura pretende mostrar que el reforzamiento teórico de esta cuestión se debe a una operación análoga a la llevada a cabo por Kant en su dialéctica trascendental. En 1972 cabe, pues, entender que la crítica de la totalidad esbozada en 1964 se registra sobre una superficie de inscripción kantiana. Sin embargo, entre ambos seminarios hay un cambio de enfoque importante. JacquesAlain Miller señala, en su artículo "Los seis paradigmas del goce", que en el Seminario XX desaparecen todos los términos que implican una conjunción -Otro, Nombre-del-Padre, Falo- o, si se conservan, dejan de considerarse términos primordiales o trascendentales, condicionantes de toda experiencia posible, para quedar reducidos a meros conectores. Lacan ya no hablará tanto en términos de causa ${ }^{8}$ porque lo que le interesa ahora es subrayar la potencia crítica de la disyunción, la no-relación -entre el significante y el significado, entre el goce y el Otro, entre el hombre y la mujer-. En la intersección sitúa el conjunto vacío, y sólo en un segundo momento comparecen en ese intersticio una serie de términos, contingentes y variables, que son suplencias - sin titular- destinadas a gestionar temporalmente el abismo. En este seminario se cuestiona abiertamente el concepto mismo de lenguaje y se toma como punto de partida explícito el goce, hasta entonces secundario o dependiente en cierto modo del significante. Son el lenguaje y su estructura los que pasan ahora

\footnotetext{
5 «Les he dicho, en suma, que no hay falta en lo real, que la falta no es aprehensible sino por el intermedio de lo simbólico. Es en el nivel de la biblioteca que podemos decir: aquí, tal volumen falta en su lugar. Ese lugar es un lugar designado por la introducción previa de lo simbólico en lo real. Este hecho, la falta de la que aquí hablo, el símbolo la colma fácilmente, designa su lugar, designa su ausencia, presentifica lo que no está ahí». J. Lacan, Le Séminaire, livre X. L'angoisse, Paris, Seuil, p. 156. Sesión del 30/01/1963.

6 J. Lacan, Le Séminaire, livre XI, p. 186. Sesión del 27/05/1964.

7 Ibidem, p. 187.

8 Para un análisis en profundidad de las razones por las que la noción de causa no es en último término pertinente para abordar la cuestión de la sexualidad, ver M. David-Ménard, Éloge des hasards dans la vie sexuelle, Paris, Hermann, 2011. No obstante, es preciso señalar que en los seminarios X y XI (L'angoisse y Les quatre concepts fondamentaux de la psychanalyse) Lacan había logrado construir un concepto de causa donde el hueco, el agujero o la interrupción son, por oposición a lo que sucede en la ley, lo fundamental.
} 
a ser considerados secundarios y derivados, semblantes cuya función es la de rellenar -abocados siempre al fracaso- los huecos que originariamente presenta el goce. Si en la primera etapa de la enseñanza de Lacan las relaciones - estructurales- eran previas a los términos, eran elementos trascendentales y constituyentes de toda objetividad y subjetividad, ahora lo trascendental es la no-relación, pues es lo que en última instancia posibilita todo tipo de invenciones y experimentaciones en un campo en el que ya no hay relaciones previas a priori y universales sino puro potencial de reglas singulares y contingentes construidas ad hoc para cada caso. Como señala Miller, esto implica un paso desde un enfoque trascendental a un enfoque pragmático que, sin dejar de ser trascendental -pues continúa interrogándose acerca de las condiciones de posibilidad-, pone el acento sobre los mecanismos de invención y creación en el vacío de la no-relación. «En lugar de los términos de estructura trascendentales, que pertenecen a una dimensión autónoma previa a la experiencia y la condicionan, tenemos el primado de la práctica. Allí donde había estructura trascendental tenemos una pragmática» ${ }^{9}$.

El Seminario $X X$ culmina todo el proceso de transición desde el anverso simbólico hacia el reverso real de la estructura al limitar definitivamente el imperio de ésta oponiéndole la no-relación. La estructura se explicaba apelando a un conjunto de relaciones o articulaciones necesarias y universales entre significantes; el giro a lo real descubre sus fallas y fisuras, cuestiona esa universalidad y necesidad y detecta no-relación -y, en todo caso, semblantes o artefactos ad hoc- allí donde antes se reclamaban relaciones constituyentes; lo constituyente, ahora, es la no-relación, la inconsistencia, la dislocación. Esto no entraña no obstante que el problema de la síntesis se haya resuelto disolviéndose, afirmando perentoriamente su imposibilidad, sino que lo que de entrada parecían dos elementos cuya conjunción había que explicar se distribuyen ahora en dos estratos diferentes: uno de ellos -lo realse descubre como siendo la condición del otro -lo simbólico-imaginario-, como siendo el hueco o el agujero mismo sobre el que se opera la síntesis.

\section{El imposible negocio redondo}

En las últimas páginas del Banquete, Alcibíades relata frustrado su tentativa de seducir a Sócrates: él creía inicialmente que si complacía a su maestro, podría como contrapartida «oír todo cuanto él sabía»; es decir, su intención era intercambiar su belleza física $-\mathrm{y}$, si fuera necesario, llegado el caso complementarla con cualquier otra cosa de su patrimonio o de sus amigos- por la belleza inteligible de Sócrates, «cambiar belleza por belleza». Pero Sócrates no accede a lo que a primera vista parece un negocio redondo, y sin embargo tampoco rechaza la proposición de Alcibíades; se limita a neutralizar la estrategia de su pretendiente haciendo explícitos los presupuestos de la transacción y cuestionando su rentabilidad: «pero, mi feliz amigo, examínalo mejor, no sea que te pase desapercibido que no soy nada $\gg 10$. Con esta advertencia pone en tela de juicio la viabilidad misma de ese trueque que

9 J. A. Miller, "Les six paradigmes de la jouissance", en La Cause freudienne, n43, octobre 1999, p. 18.

10 Platón, Banquete, 219a1-ss. Seguimos la traducción de M. Martínez Hernández para la edición de Gredos (Platón, Diálogos III. Fedón, Banquete, Fedro, Madrid, Gredos, 1997). 
postula la belleza y la sabiduría como mercancías, objetos de intercambio -inventariables dentro del patrimonio propio-. Sucede, previene Sócrates, que la persecución de la presunta ganancia que obtendrían los comerciantes lleva aparejado un «enorme riesgo»: puede ocurrir que, una vez realizado el intercambio, se den cuenta de que en realidad no han obtenido nada a cambio de sus propios favores. Y es que la sabiduría podría no ser tal, no ser, podría fallar y no corresponder11, pues jamás está segura de sí misma; mucho menos, por ende, cabe tomarla por un objeto de intercambio. La lógica reificante de Alcibíades, «que admite la sabiduría como un haber, como una cosa, una res» ${ }^{12}$, que hace del Otro empresario y producto a la vez, queda de esta forma suspendida.

En las conferencias introductorias a la filosofía que pronunció en 1964 y que han quedado recogidas en el volumen Pourquoi philosopher?, Lyotard analiza las consecuencias de la creencia en la posibilidad de un negocio redondo: el negocio es en realidad una apuesta, pero una apuesta en la que en el mejor de los casos nos quedamos igual que antes y en el peor, sufrimos «una dura pérdida». «La situación no es la de una compra al contado, sino la de una compra a crédito en la que el deudor, Sócrates en este caso, no es solvente a ciencia cierta» ${ }^{13}$. El problema no es simplemente que esta lógica reificante comercie con mercancías que no son tales, sino que establece gracias a la hipoteca todo un sistema de sometimiento, desigualdad y esclavitud. Alcibíades cuenta cómo ante la reacción de Sócrates «no encontraba una salida, [...] era su esclavo como nunca nadie lo había sido de alguien, no hacía más que girar en torno a él como un satélite» 14 . Ahora bien, en toda esta historia no es Sócrates el amo o el agente del esclavismo -ni tampoco el siervo atado a la deuda-, pues en verdad no ha entrado en la apuesta, no ha querido jugar; «él no tiene juego» ${ }^{15}$. Sócrates no está regateando ni es un negociante más sutil, como piensa Alcibíades, a quien Lyotard describe como «el mercader de alfombras que corre tras el comprador obstinado en su oferta de 50.000 para decirle: tened, os la regalo por $55.000 » 16$. Lo que introduce todo el régimen de sometimiento es la organización del deseo de Alcibíades -la confusión del objetocausa del deseo con un objeto empírico17-, es la ilusión trascendental que le hace juzgar

\footnotetext{
11 «No es la belleza ni la ascesis ni la identificación con Dios lo que desea Alcibíades, sino ese objeto único, ese algo que ha visto en Sócrates y del que Sócrates le disuade porque Sócrates sabe que no lo tiene». J. Lacan, Le Séminaire, livre VIII. Le transfert, versión inédita de la École Lacanienne de psychanalyse, sesión del 08/02/1961.

12 J. F. Lyotard, Pourquoi philosopher? Paris, PUF, 2012, p. 37.

13 Ibidem, pp. 33-34.

14 Banquete, 219d-e.

15 J. F. Lyotard, Op. cit., p. 34.

16 Ibidem, p. 35.

17 El deseo, como expone Lacan en su Seminario VII. La ética del psicoanálisis, no se puede explicar por los objetos empíricos hacia los que se inclina ni por la voluntad del sujeto, y tampoco las cadenas significantes y las cargas simbólicas de la estructura, por mucho que actúen como ley a priori, permiten dar cuenta hasta sus últimas consecuencias de su movimiento. El principio trascendental reside en otra parte, en un Afuera absoluto: la Cosa y el objeto $a$ asumen tal papel, y si bien el objeto $a$ estará presente en la enseñanza de Lacan hasta el final, el concepto de das Ding desaparece después del Seminario VII. A principios de los años cincuenta, la $a$ era para Lacan el otro del espejo, del reflejo especular, pero esa misma inicial cambia radicalmente de función a partir del giro a lo real: la letra $a$ -que no significa ya nada, aunque connote numerosas cosas- rescata ahora lo que comparece en el
} 
posible ese negocio redondo, creer en una totalidad alcanzable por medio de ese intercambio - es lo que le induce a apostar sus cartas, a sumar si es preciso nuevos bienes a su belleza, a comprar finalmente a crédito con el único aval de su libertad-.

El discurso de Aristófanes, unas páginas más atrás en el diálogo platónico ${ }^{18}$, narraba el mito del andrógino, de esas personas «redondas en su totalidad», el genuino negocio redondo que fue impugnado por la ira de Zeus cuando los individuos esféricos intentaron escalar hasta el cielo. Tras el pecado de hybris y el castigo de la división, el amor intentaría «hacer uno solo de dos» y restañar así la añoranza de cada parte hacia su otra mitad. Sin embargo, Diotima duda de que esta lógica sea la que explica el amor: «según mi propia teoría, el amor no lo es ni de una mitad ni de un todo». No hay mitades porque no hay todos, ni en la fusión de dos partes pretendidamente complementarias ni en las propias partes. Lo que hay, podría no haberlo, no es un haber, una cosa, una $\operatorname{res}^{19}$. Y es creer en esos haberes o, mejor dicho, invertir libidinalmente en ellos, en su totalidad actual o potencial, lo que mantiene esclavo a Alcibíades.

No obstante, no es sólo en el lecho donde Sócrates sigue pasando, pese a su distanciamiento, por un jugador más sofisticado, por un especulador o broker de altos vuelos -que, en realidad, por mucho que prometiera "el negocio del siglo", necesitaría del desequilibrio para enriquecerse-; lo que cree Alcibíades lo creerán también los atenienses. En un momento dado de su discurso, Alcibíades compara a Sócrates con «esos silenos existentes en los talleres de escultura [...] que, cuando se abren en dos mitades, aparecen con estatuas de dioses en su interior» ${ }^{20}$. El recelo ante Sócrates no es sólo porque esté jugando con mayor inteligencia, sino además porque parece estar ocultando algo, guardando un as en la manga. Así, junto con la ilusión de la totalidad, viene a alinearse en esta lógica de la esclavitud la convicción de que el Otro - tradicionalmente la mujer- esconde un enigma. La respuesta de Sócrates al juicio de los atenienses consiste, como propone Lyotard, en abrir ese sileno y dejar al descubierto su vacío, su propia vacancia -en definitiva, su propia libertad-: «acepta beber la cicuta; porque si hubiera desorientado al adversario sólo para pillarlo mejor, para

espejo como punto ciego junto con el precipitado de la imagen. Más allá del objeto imaginario hay un objeto que no se deja reflejar. En El deseo y su interpretación, el Seminario VI (1958-1959), aparece por primera vez este cambio de sentido, pero es más bien a partir del curso siguiente cuando se formula de manera explícita. El acento se traslada, por tanto, de la imagen en el espejo y su plataforma simbólica a la presencia de un objeto inconcebible que no se deja apresar, la presencia de algo Unheimlich, inquietantemente extraño, que, pese a su extrañeza, constituye de algún modo el contenido de la intuición del deseo - un contenido que en realidad no es nada, que no tiene consistencia ontológica pues no concurre sino como el fallo de la imagen y el símbolo- y, desde ahí, se erige como principio explicativo de toda subjetividad y objetividad. Este resto de lo real que perturba las estructuras simbólicas e imaginarias es lo que pone en movimiento todo deseo, toda curiosidad, todo pensamiento -es lo que a partir del Seminario XVII. El reverso del psicoanálisis Lacan denominará, en paralelismo con la plusvalía marxiana, plus-de-gozar-. Desde esta perspectiva, habría un uso legítimo y un uso ilegítimo del objeto $a$ : un uso regulativo que no lo hipostasiaría, que se limitaría a concebirlo como lo que causa y hace posible la dinámica del deseo, y un uso trascendente que lo transformaría en un objeto efectivo, empírico -real o mítico-, de deseo.

18 Banquete, $189 \mathrm{~d}-\mathrm{ss}$.

19 F. Lyotard, Op. cit., p. 37.

20 Banquete, 215a-b. 
dominarlo, no hubiera aceptado morir. Muriendo voluntariamente les obliga a pensar que verdaderamente no tenía nada que perder, que él no tenía nada en su juego» 21 .

El punto de partida del pensamiento de Lacan en el Seminario $X X$ es precisamente ese vacio que deja Sócrates, y se encomienda a la tarea de denunciar cualquier intento de llenarlo 22 . No obstante, partir de un vacío torna imposible la partida misma, pues o bien se está siempre ya en el segundo paso, o bien la tentativa de dar el primero nos sume en el abismo. Esta intuición es la que empujó a Lacan a tachar en 1959 la letra que en su álgebra representa al Otro: A de Autre. Con este gesto, deja huérfano a su alfabeto; como en el Talmud babilónico, cuyos tratados empiezan siempre por la página 2, ya no hay algo así como una primera página, un primer principio del que partir, una primera letra que dé el pie para comenzar. «No hay Otro del Otro» es la fórmula que traduce la A: no es sólo que el comienzo y el centro se sustraigan permanentemente por el hecho de que la constitución de la identidad propia dependa siempre de Otro -el otro imaginario del espejo con el que se identifica el bebé, el otro simbólico de la palabra que nombra y gesta con el nombre todo un mundo-, sino que ese "Otro lugar" donde todo empieza -y por tanto nunca termina de empezar, en la medida en que siempre empieza en otra parte de la que cabría esperar- es un lugar en constante precariedad, un lugar que, como la sabiduría de Sócrates, podría no ser, un lugar sin garantías. Si el Otro se distingue por algo no es por ser Otro entre todos o por ser único, «sino sólo porque podría no haberlo» 23 .

Cuando Lacan aborda la cuestión de la relación sexual y de la diferencia entre las posiciones masculina y femenina, este primer gesto del Otro caído queda vinculado de modo explícito con la formulación de dos axiomas más que inciden en esta pulsión del "No": «La relación sexual es imposible»-y aquí no habrá signo algebraico que valga, pues en tanto que imposible no se deja escribir-y «La mujer no existe»-abreviado «ta mujer»-. De nuevo, el punto de partida será el No, la inexistencia, el vacío, el silencio de una ausencia, de una imposibilidad, de una incompletud estructural - ¿cómo completar o terminar lo que ni siquiera ha comenzado?-.

\section{2. «Suerte que ha fracasado, que nada ha empezado, nunca hubo nada más que nunca y nada, es una verdadera suerte, nada nunca» 24}

Una de las intuiciones fundamentales del psicoanálisis es aquella que registra que al vacío se accede de modo privilegiado a través de lo que falla o no encaja. «El análisis se

21 F. Lyotard, Op. cit., p. 37.

22 Las figuras topológicas de Lacan recogen ya esta imposibilidad del negocio redondo. Ninguna de ellas es una esfera; tanto el toro como la banda de Möbius son superficies atravesadas por un corte o por un agujero, impugnan en sí mismas la idea de totalidad.

23 J. Lacan, Le Séminaire, livre XVI. D'un autre à l'autre, versión inédita de la Association Freudienne Internationale, sesión del 11/06/1969.

24 S. Beckett, Textes pour rien, en Nouvelles et textes pour rien, Paris, Minuit, 1958, p. 200. 
ocupa muy especialmente de lo que no funciona; es una función todavía más imposible que las demás, pero gracias a que se ocupa de lo que no funciona, se ocupa de eso que hay que llamar por su nombre, y debo decir que soy el único que lo ha llamado así, y que se llama lo real» 25 . Si Lacan emprende una investigación acerca de lo que fracasa no es, por tanto, con el objetivo de suturar, reparar o normalizar -como sí pretende la Ego-psychology contra la que él mismo batalla-, sino para explorar el hueco que dejan sus noes. El fracaso condensado en las palabras de Beckett es así una «suerte», la fortuna (tyché) que conduce a un lugar distinto del comienzo o del fundamento, un lugar privilegiado para encontrarse con lo real. El primero de los fracasos -y el que se va a convertir en el paradigma de todos los demás- que estudia Lacan a partir de 1964 y al hilo de la clínica es el trauma, que denominará, precisamente por esta complicidad entre el fracaso y el vacío, «troumatisme» 26 (agujero/trauma). El trauma es en términos generales el agujero del encuentro con lo real, la imposibilidad de inscribir ese encuentro en unas coordenadas previas, y las dos dimensiones donde se hace más palmaria esa imposibilidad, donde el cabo suelto y la insatisfacción son lo más frecuente, son la sexualidad y el lenguaje.

Lacan recoge de Freud la sospecha de que lo verdaderamente importante no se juega en los pequeños triunfos cotidianos -en los que, por ejemplo, logramos transmitir un mensaje y comprar con eficacia un kilo de manzanas o invitar a alguien a cenar-, sino en los acontecimientos cuya memoria se resiste a abandonarnos porque no estamos seguros de haber dicho exactamente lo que queríamos decir-quizás porque tememos que las palabras hayan dicho más o menos de esa cantidad precisa- o de haber hecho lo que queríamos hacer -para sentirnos totalmente satisfechos en la relación con otra persona-. Y no es sólo que lo que más preocupa se encuentre en el segundo grupo, sino que además suele ser lo más habitual: frente a las consignas publicitarias que prometen la facilidad del «negocio redondo», la dificultad e incluso la imposibilidad tienden a ser lo normal. El énfasis cae sobre lo que «puede leerse de una infinidad de maneras distintas. Y precisamente por eso se lee mal, o a trasmano, o no se lee» 27 .

Una vez más, ante lo difícil la estrategia analítica no busca iluminar el camino fácil, la interpretación verdadera o la adaptación; ante la complejidad de decir y de encarnar una determinada identidad sexual, lo que persigue el psicoanálisis es detectar el origen, los engranajes y las razones de esa dificultad. Con este fin, Lacan se remonta al vacío y a eso que se lee mal e incluso no se lee, al lugar donde el sentido está a punto de desvanecerse, de no querer decir nada. La lógica y la formalización que pondrá en juego ya no aspiran tanto a convertirse en expresión adecuada y abstracta de una determinada realidad cuanto a teorizar los límites de la ley, el hecho de que no funciona bien, fracasa o es no-toda.

\footnotetext{
25 J. Lacan, “La Troisième”, en Lettres de l'Ecole freudienne, n¹6, 1975, pp.177-203. Continúa: «La diferencia entre lo que funciona y lo que no funciona es que lo primero es el mundo: el mundo va, gira, es su función de mundo. Para darse cuenta de que no hay mundo, es decir, de que hay cosas que sólo los imbéciles creen que están en el mundo, basta señalar que hay cosas que hacen que el mundo sea inmundo, si puedo expresarme así; es de eso de lo que se ocupan los analistas».

26 J. Lacan, Le Séminaire, livre XXI: Les non-dupes errent, versión inédita de la Association Freudienne Internationale, sesión del 19/02/1974.

27 J. Lacan, Le Séminaire, livre XX: Encore, Paris, Seuil, 1975, p. 37. Sesión del 09/01/1973.
} 
En la primera etapa de su enseñanza, centrada en la exploración del orden simbólico, Lacan define el significante por «no significar nada, gracias a lo cual es capaz de dar en cualquier momento significaciones diversas»28. Asimismo, su relectura de Saussure está ya marcada por el privilegio de la dificultad, en la medida en que, por ejemplo, interpreta la barra que media entre el significante y el significado en el algoritmo del signo (S/s) no ya como la operación de significación sino como «una barrera resistente a la significación» 29 . Así, el sentido que opera al borde de su propio fracaso ${ }^{30}$ se revela como la única plataforma sobre la que cabe construir cualquier significado; el vacío, la imposibilidad que explora Lacan no es sólo un caso límite, sino el lugar de toda génesis ulterior. «Lo que cabe decir es que no hay precisamente más que no-posible en el origen de toda enunciación» 31 . Pero en tanto que fuente de cualquier invención, alberga también el riesgo constante de caer en la mitología de la totalidad que lastraba a Alcibíades, de ahí que el retorno al punto desvaneciente del sentido cumpla una función crítica.

La sexualidad, como el lenguaje, se mueve también en esta área de inestabilidad, y es únicamente de manera mítica que cabe hablar de satisfacción y completud. No es sólo que en la conjugación de dos posiciones sexuales se dé una cierta dislocación, sino que cada una de esas posiciones es en sí misma una forma específica de inconsistencia. Sin embargo, cuando se toman las categorías "masculino" y "femenino" por parcelas absolutas y complementarias de una división, todo aparenta ser mucho más fácil. Contra esta fantasía se alza la pulsión del "No" de Lacan, cuya intención es explorar la propia imposibilidad en tanto que fuente de toda posibilidad ulterior, de todo lo que se invente y construya sobre el vacío incolmable de la relación sexual imposible, del Otro o La Mujer inexistentes.

Monique David-Ménard, en su libro Éloge des hasards dans la vie sexuelle, estudia el peculiar estatuto de la sexualidad en un diálogo crítico con Lacan. Recoge la idea de que la relación sexual es del orden del encuentro, de la tyché o el azar sin regla ni patrón, y en tanto que tal entraña una disimetría fundamental - mejor que una desproporción, pues ésta alude todavía a una medida que en el encuentro con lo real falta por completo- entre varios elementos: no sólo entre los partenaires, sino también entre el goce sexual y la palabra, o entre el amor y el deseo. Tanto el objeto de la atracción como la relación que se establece con él desbordan el marco simbólico en el que se inscribe la historia; ambos pertenecen a la dimensión de lo real, de lo imposible. Los desengaños amorosos -el fracaso, de nuevo- son, señala David-Ménard, la circunstancia donde más patente se hace el vacío sobre el que se instala el encuentro, «el vacío, la angustia y el miedo de no ser nada toman el relevo de la intensidad de la existencia experimentada» ${ }^{32}$.

28 J. Lacan, Le Séminaire, livre III. Les psychoses, versión inédita de la Association Freudienne Internationale, sesión del 11/04/1956 (la cursiva es nuestra).

29 J. Lacan, "L'instance de la lettre dans l'inconscient ou la raison depuis Freud", en Écrits, Paris, Seuil, 1966, p. 497.

30 «El sentido indica la dirección hacia la cual él fracasa». J. Lacan, Le Séminaire, livre XX. Encore, ed. cit., p. 74. Sesión del 13/03/1973.

31 J. Lacan, Le Séminaire, livre IX. L'identification, versión inédita de la Association Freudienne Internationale, sesión del 07/03/1962.

32 M. David-Ménard, Op. cit., p. 16. 


\subsection{Las fórmulas de la sexuación}

En el Seminario $X X$, Lacan asume el reto de hablar de lo imposible y a la vez depurarlo, cuanto se pueda, del lastre imaginario y simbólico que pretende retrotraerlo a lo posible; es decir, más allá de su representación, busca su pura presentación ${ }^{33}$, más allá de su significado, busca su transmisibilidad. Para ello, pondrá en juego una serie de expresiones formales a las que dará el nombre de matema, un signo algebraico que no está hecho tanto para ser comprendido cuanto para ser usado - no se sabe en absoluto qué quiere decir, pero se transmite integralmente ${ }^{34}$.

La premisa de la que parte Lacan a la hora de abordar la sexualidad es que la diferencia sexual, la relación sexual y las posiciones sexuales deben ser pensadas desde la imposibilidad; de entrada, desde la radical imposibilidad de ser simbolizadas -y no pueden ser pensadas de otra manera-. Lacan comienza, pues, por escribir acerca de la imposibilidad misma de escribir, y por denunciar como falsas las oposiciones simbólicas de categorías inversas y complementarias -activo/pasivo, intelectual/sensible, racional/irracional, etc.- que se han arrogado tradicionalmente el derecho de representar lo que en verdad es irrepresentable. Pero además no es sólo que la relación sexual no se pueda escribir; la relación sexual, sienta Lacan, no existe, y no porque no la haya pero quizás la pudiera llegar a haber, sino porque ella misma es rigurosamente imposible. Para investigar la diferencia sexual es preciso, por tanto, cuestionar y alejarse de las simbolizaciones dicotómicas y de las identidades imaginarias que se adhieren al cuerpo como una segunda piel; antes que nada, hay que remontarse un paso atrás, «vaciar lo real» 35 . Es desde esta perspectiva que Lacan preferirá hablar de fórmulas de la sexuación, de lógica y no de teoría -y menos aún de ontología ${ }^{36}$ -

La particular lógica de la sexuación de Lacan toma como piedra de toque un primer "No": «No hay relación sexual». No se trata de una verdad fáctica ni de una descripción empírica, sino de una afirmación trascendental que recoge la inexistencia de una estructura universal para el amor sexuado - trascendental en la medida en que esa inexistencia se alza como la condición de posibilidad de todo encuentro y creación, siempre contingentes, en el terreno de la sexualidad-. Como señala Monique David-Ménard ${ }^{37}$, rapport, además de relación, significa informe, de modo que declarar la imposibilidad de la relación sexual es hacerse cargo de la imposibilidad tanto del encuentro - a no ser fallido- cuanto de aquello

33 B. Ogilvie, Lacan. La formation du concept de sujet (1932-1949), Paris, PUF, 3ème édition, 1993, p. 118.

34 «No se sabe en absoluto qué quieren decir, pero se transmiten». J. Lacan, Le Séminaire, livre XX. Encore, ed. cit., p. 100. Sesión del 08/05/1973.

35 «No hay verdad como tal posible más que la de vaciar lo real». J. Lacan, Le Séminaire, livre XXIII. Le sinthome, Paris, Seuil, 2005, p. 31. Sesión del 09/12/1975.

36 En una entrevista recogida al final de Le triomphe de la religion (Paris, Seuil 2005), Lacan responde contundentemente a esta cuestión: «-En su filosofía.../ Yo no soy en absoluto un filósofo. - Una nozione ontologica, metafisica del reale.../No es en absoluto ontológica» (p. 96). Si en los años sesenta Lacan todavía vinculaba lo real a una cierta ontología, diez años más tarde dejará sistemáticamente de hablar del ser con el fin de evitar cualquier posible hipóstasis de las funciones lógicas con las que trabaja.

37 M. David-Ménard, Éloge des hasards dans la vie sexuelle, p. 62. 
que lo haría inteligible, aquello que sintetizaría la clave de lo que allí ocurre. «Se trata de la experiencia del fracaso a la hora de encontrar en el otro lo que se busca a título de complemento [...]. Nada hace relación [fait rapport] en un encuentro» ${ }^{38}$. Frente a la lógica tradicional, encaminada a inventariar y codificar las relaciones válidas entre proposiciones, la lógica de Lacan se ocupa precisamente de lo que queda fuera de ella, a saber: la no-relación. Es estrictamente imposible escribir o formalizar la relación sexual como una relación entre dos variables $(x R y)$; «no hay elaboración logicizable y al mismo tiempo matematizable de la relación sexual»39. Primero, porque no hay variable alguna que permita simbolizar la posición masculina o la posición femenina y, segundo, porque aun en el caso de que la hubiera, no cabría encontrar ninguna función que pusiera directamente en relación los dos términos. La relación sexual es relación entre los animales, pero en el momento en que intervienen la palabra y la sexualidad humanas, aquélla deviene imposible; ya no cabe cuadrar las posiciones disimétricas del encuentro. El pasaje de un estado al otro tiene lugar por mediación de una ley: al introducir un orden -el orden simbólico- se introduce al mismo tiempo un afuera que, además de aparecer como resto insimbolizable, se descubre como el abismo que simultáneamente hace posibles e imposibles -porque los frustra constantemente- las construcciones y artificios simbólico-imaginarios.

Cuando la sexualidad entra en el lenguaje, la relación libidinal no se establece ya con otro sujeto sino con una entidad en principio lingüística -que, en cuanto tal, nunca termina de satisfacer, pues uno nunca encuentra allí exactamente lo que espera-. Lacan va a denominar a esa entidad mediadora primero "falo", después "función fálica" y por último "función $\Phi "$ ". La carga simbólica del falo 40 lo hacía de entrada apto para figurar la relación sexual o, con más propiedad, el hiato que la constituye, pero es precisamente esa carga simbólica la que va a forzar que quede postergado como término en beneficio de una pura función algebraica o fórmula abstracta capaz de denotar una instancia que no significa nada pero que puede llegar a significar cualquier cosa. «Es el significante que no tiene significado» 41 .

\section{Idem}

39 J. Lacan, Le Séminaire, livre XXII. R.S.I., versión inédita de la Association Freudienne Internationale, sesión del 18/03/1975. Vid. también J. Lacan, Le Séminaire, livre XX. Encore, ed. cit., p. 4. Sesión del 09/01/1973: «En rigor, podría escribirse $x R y$, y decir que $x$ es el hombre, $y$ la mujer y $R$ la relación sexual. ¿Por qué no? Únicamente porque es una necedad, ya que lo que se sustenta bajo la función de significante, de hombre y de mujer, no son más que significantes enteramente ligados al uso cursocorriente [courcourant] del lenguaje».

$40 \mathrm{El}$ falo, como aclara en diversas ocasiones Lacan, no es el pene y no tiene que ver con el órgano masculino. En todo caso, la diferencia anatómica sólo sirve para figurar, y no para determinar, la diferencia sexual, sólo sirve para poner un rostro visible a lo imposible.

${ }^{41}$ J. Lacan, Le Séminaire, livre XX. Encore, ed. cit., p. 74. Sesión del 13/03/1973. Para ilustrar el carácter constituyente que el recorrido de los significantes tiene para el sujeto, Lacan utilizó en su Seminario II. Los escritos técnicos de Freud el cuento de Edgar Allan Poe La carta robada. Como es de sobra conocido, esa carta que circula y cuyo contenido nunca es revelado es para él encarnación del significante por excelencia, el significante sin significado, el significante que marca la sumisión de los sujetos al orden simbólico -su castración, pues ya ni siquiera son «dueños y señores de su propia casa», sino que han de obedecer a la ley si quieren ser algo; pero también la posibilidad de que la necesidad animal (de beber, de dormir, etc.) se transforme en deseo gracias a la capacidad de formularla en palabras- y su separación irreversible del mundo de las cosas-en-sí, a saber: la función fálica. Esta 
Ahora bien, el falo no es tampoco puramente simbólico, en la medida en que, como significante de la falta, arraiga en el punto imposible de intersección entre lo simbólico y lo real. La relación libidinal se establece con ese objeto paradójico en tanto que éste encarna la falta -el vacío sin pérdida ni carencia- que causa el deseo y las construcciones significantes.

Así, pues, antes de formalizar estas conclusiones, Lacan advierte que lo que los individuos toman por el goce fruto de una relación sexual no es más que el goce que resulta de la relación con la función fálica; se goza del falo, no del sexo ${ }^{42}$. El distinto modo de posicionarse ante esta función va a ser el criterio con el que Lacan caracterice la diferencia sexual. Esta diferencia se presenta de entrada como una división legislativa -ilustrada en sus primeros años de enseñanza por la ley de la segregación urinaria que imponen los carteles "damas" y "caballeros" en la puerta de los lavabos- que crea y reproduce sus propias categorías, y en modo alguno como una distinción esencial derivada de la biología o la anatomía -afirmará en numerosas ocasiones que los procesos de identificación son independientes del sexo biológico, que, por ejemplo, un individuo nacido con atributos masculinos puede perfectamente situarse en la posición femenina y cambiar en diversos momentos de posición-. No obstante, al profundizar en esta caracterización se hará patente que la diferencia sexual no es tanto la construcción discursiva o simbólica que precipita cuanto la inestabilidad que afecta a esa construcción, a saber: el propio fallo de la simbolización. De ahí que desde esta perspectiva no sean pertinentes las críticas que acusan a Lacan de hiper-lingüistizar la realidad humana, en la medida en que si bien analiza la implantación de una determinada ley simbólica, inmediatamente descubre en esa implantación los fracasos y las paradojas que como veremos la sostienen.

La lógica de la sexuación distribuye cuatro fórmulas en dos pares de oposición, arribaabajo e izquierda-derecha:

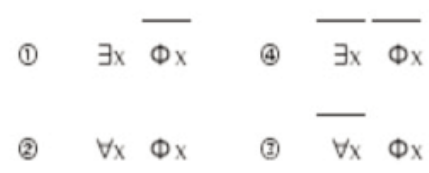

Pese a la utilización del cuantificador universal, Lacan no va a convocar la universalidad -o la totalidad - sino para negarla de dos maneras distintas. Los dos modos de decir "no" al todo van a ser los que determinen las posiciones masculina y femenina. La posición masculina ocupa la parte izquierda, y postula que la relación con la función fálica $(\Phi x)$ se establece sólo a partir de una existencia que la niega. Para que todos los seres se sometan a la ley $(\Phi x)$ es preciso que haya un fuera-de-ley, una excepción a la regla, un $x$ que no $\Phi x$. Lacan utiliza el mito freudiano de Tótem y tabú para explicar la dinámica de la posición masculina: existió una vez un sujeto para el que no regía la ley, el padre de la horda que podía gozar irrestrictamente de todas las mujeres, y gracias a esa figura que marca el afuera se hace posible delimitar los contornos de la universalidad ulterior, los límites de todos

misma carta organiza la interacción entre los personajes del cuento, de modo que no hay relación de los sujetos entre sí, sino en todo caso de los sujetos con ese significante.

42 «El goce, en tanto sexual, es fálico, es decir, no se relaciona con el Otro en cuanto tal». J. Lacan, Le Séminaire, livre XX. Encore, ed. cit., p. 14. Sesión del 21/11/1972. 
los sujetos que, esta vez sí, van a estar sometidos sin excepción a la ley. La función fálica se establece, al menos en el tramo izquierdo de la tabla, sobre el requisito de su propia negación, de una excepción. Lo que la primera fórmula contiene es la condición para poder hacer una afirmación universal en el piso de abajo: para poder enunciar un universal es preciso que se establezca un límite a esa universalidad, es preciso delimitar cuál es el perímetro de su aplicación; se postula una existencia que niega la función fálica para que ésta pueda tener, más acá del límite, validez universal. Una vez más, primero el "no": primero es la existencia que tacha de falsa la función fálica, y sólo sobre esta afirmación cabe después fundar la verdad y la universalidad de esa misma función; la afirmación inicial de su falsedad hace posible su verdad. El todo, pues, no es sin su excepción: la excepción particular da cuerpo al Universal a la vez que niega su propiedad constituyente. Desde esta perspectiva, lo que hace hombre al individuo que se identifica con esta lógica es su aceptación de la castración, su sometimiento a la ley, pero ese sometimiento queda vinculado a la certeza de que al menos uno, el padre de la horda primitiva, no se sometía a la castración. Así, la función fálica se impone de manera paradójica, pues se impone sólo si supone a la vez una excepción, es decir, sólo si de algún modo se auto-limita, sólo si la totalidad o la universalidad tienen una cláusula de exención.

En el lado derecho de las fórmulas es quizás más patente la negación de lo universal, pues el cuantificador aparece él mismo negado. Sin embargo, el "no" del que parte la posición femenina es el de la fórmula superior, el que paradójicamente afirma que no hay una sola existencia que no esté sometida a la función fálica. Esta función hace aguas aquí por la razón opuesta que en el caso anterior: no termina de implantarse precisamente porque no hay excepción que se lo permita, no hay límite que posibilite la determinación de un conjunto. La posición femenina socava la universalidad de la función fálica por el hecho de no presentar excepción alguna. De ahí que Lacan afirme que «La mujer no existe», que no hay una categoría universal en la que se puedan subsumir todas las mujeres particulares; más bien, cuando se dice "La mujer" no cabe hacer conjunto sino invocándolas una por una. En definitiva, al no poder constituirse la clase de las mujeres tampoco aquí se puede hablar de totalidad. Y lo que el piso inferior afirma es la conclusión: la mujer es no-toda, no todo de la mujer se rige por la función fálica. No existe ninguna mujer que no se relacione con la función fálica, pero no es todo de una mujer lo que está sometido a esta función. El hecho de que el cuantificador universal intervenga de manera negativa en la posición femenina traduce el «La mujer no existe» - "La mujer” es una fórmula desprovista de sentido, no significa nada- o «ta mujer», que es la única manera de escribir esta no-clase o no-toda. El intento de determinar la posición femenina desemboca así en un fracaso: no es posible decir universalmente en qué consiste ser mujer; entre las mujeres y lo universal, Lacan instaura una no-relación. Además, que "La mujer" no exista no sólo significa que la feminidad no puede verterse en una categoría universal, sino también que la posición sexuada de las mujeres no es en modo alguno, como la fantasía masculina pretende, una excepción, un "eterno femenino" pre-simbólico. El No-todo (pas tout) no es la existencia que niega la función fálica, no es la existencia de la excepción, sino más bien «una existencia indeterminada» ${ }^{43}$. Sucede aquí lo mismo que en el caso del juicio infinito de Kant, que no es un juicio negativo sino

43 J. Lacan, Le Séminaire, livre XX. Encore, ed. cit., p. 94. Sesión del 10/04/1973. 
un juicio donde el "no" es especial y no determina: «el alma es no-mortal» es una afirmación que sitúa al alma en el campo ilimitado de los seres que no mueren ${ }^{44}$. Del mismo modo, «La mujer es no-toda» ubica a la mujer en un campo ilimitado, y no la convierte en lo contrario u opuesto, no la determina como el reverso de lo masculino.

Desde estas coordenadas, resulta fácil trazar un paralelismo entre la afirmación «No hay Otro del Otro», que dejaba sin garantías al lenguaje y a la verdad, y la sentencia «La mujer no existe», pues como sostiene Jacqueline Rose, «la cuestión de qué es una mujer siempre se estanca en el reconocimiento crucial de que no hay absolutamente ninguna garantía de que ella sea en absoluto» ${ }^{45}$. La posición femenina pone así sobre la mesa su propia precariedad, esa misma precariedad que Sócrates manifestaba acerca de sí mismo y de su sabiduría - «no vaya a ser que no sea nada»-. La reivindicación de esta precariedad es la que puede servir de antídoto para combatir los semblantes que se enquistan como si pertenecieran al orden del ser y, en concreto, la construcción de "La mujer" con que se ha heterodesignado a un conjunto en realidad desclasado de individuos, la construcción de una categoría absoluta a la que se excluía del paradigma universal masculino a la vez que se la convertía en su Otro complementario. El sometimiento, igual que en la historia de Alcibíades, aparece cuando una de las dos posiciones se toma a sí misma por una totalidad -o casi-totalidad- positiva y define a la otra como su reverso negativo y complementario. Y como negativo del hombre, "La mujer" no es más que el objeto de la fantasía masculina, un objeto cuya absoluta alteridad permite al hombre asegurar su propia identidad. Sin embargo, la resolución «No hay Otro del Otro» denuncia la ilegitimidad de este movimiento; "La mujer" no puede, ni siquiera como objeto fantástico, ocupar el lugar de la garantía de la verdad masculina o universal, pues ese lugar ha de permanecer vacío.

En consecuencia, «La mujer no existe» es una afirmación destinada a denunciar las suplantaciones y rellenos espurios del vacío y a impedir con ello las fundamentaciones absolutas, los dogmatismos y el sometimiento. «La mujer no existe» no apunta a un modo de ser más allá del reino simbólico, no apunta a ningún "más allá" substancial; por el contrario, niega la posibilidad misma de un ente trascendente al sostener con su inexistencia un afuera abismal que no es sino hueco, abre el Sileno y muestra su vacío, preserva el presunto enigma o misterio de la mujer para desvelar que en verdad no hay misterio alguno, nada que ocultar-ningún Otro del Otro-, nada 46 .

La oposición que en la tabla de las fórmulas se da entre el lado masculino y el lado femenino, por tanto, no hace de uno de los elementos la negación del otro, sino un tipo de no-relación que impide la conjunción. El resultado del cotejo entre las distintas expresiones formales de la sexualidad es que no hay ni puede haber conjunción entre ellas, y así es como plasma Lacan la imposibilidad de la relación sexual: los dos sexos están condenados a la disyunción. Y no es que sea la mediación de la función fálica lo que obliga a la disyunción a dos partes que de poder reunirse constituirían una totalidad; más bien, esas dos posiciones

\footnotetext{
44 Vid. I. Kant, Kritik der reinen Vernunft, A 72/B 97-ss.

45 J. Rose, Sexuality in the Field of Vision, London, Verso, 1986, p. 67.

46 Esta nada no neutraliza la eficacia de las agendas políticas feministas, no las deja sin sujeto, sino que inaugura la posibilidad de inventar ese sujeto cuantas veces sea necesario y de cuantas maneras se desee -pues el vacío, el abismo, es en realidad el único lugar del que puede emerger cualquier construcción-.
} 
que se configuran y determinan en su particular relación con la función fálica son los dos modos de fracasar en la tentativa de alcanzar la totalidad. No cabe ningún "Todo" formado por la reunión de la estructura femenina y la masculina en la medida en que esas estructuras son en sí mismas una totalidad fallida, la manifestación del fracaso de la totalidad. Hay «una manera masculina de que la relación sexual falle [rater], y luego otra manera. Este fallo [ratage] es la única forma de realización de esa relación si, como yo lo planteo, no hay relación sexual. Entonces decir todo sale bien no impide decir no-todo sale bien, porque es de la misma manera: eso falla. No se trata de analizar cómo sale bien. Se trata de repetir hasta la saciedad por qué falla» 47 .

A lo largo de este desarrollo, Lacan no ha proporcionado en ningún momento una caracterización positiva de las dos posiciones sexuales, no ha elaborado ninguna lista de oposiciones binarias y complementarias entre propiedades fenoménicas; por el contrario, se ha movido exclusivamente en el terreno de la inconsistencia, de la resistencia perpetua a la caracterización $-\mathrm{y}$, por tanto, a la esencia-, del fracaso de la simbolización. Asimismo, ni siquiera ha postulado una simetría de las inconsistencias, de forma que la diferencia sexual no se resuelve en una reunión armónica, sino que más bien persiste como una pura diferencia, un diferente modo de gozar, de relacionarse con la función fálica. Ambos se determinan por relación a una y la misma función, pero no lo hacen de la misma manera. En este sentido, cuando Lacan configura su ciencia de lo real como una lógica no está violando la prohibición kantiana de que la lógica hable del ser sin pasar por la estética o por una experiencia concreta $^{48}$, ya que ese real del que se ocupa la lógica lacaniana no es sino puro vacío, pura inconsistencia, pura fisura $-\mathrm{y}$, en todo caso, la experiencia de ese vacío completa la lógica con una estética trascendental renovada-. La ciencia de lo real se circunscribe a las premisas de una lógica trascendental que no versa sobre el ser sino sobre sus condiciones de (im)posibilidad 49 . Y en tanto que trascendental, tampoco es meramente una lógica formal ${ }^{50}$; a pesar de que se sirve de las herramientas del orden de lo universal y lo necesario, las retuerce hasta hacerles decir todo lo contrario. La axiomatización y las formalizaciones acuden para escribir lo que no puede escribirse, la no-relación, la pura contingencia. Las nociones modales, en lugar de destinarse a explicitar las reglas de la deducción, se desquician

\footnotetext{
47 J. Lacan, Le Séminaire, livre XX. Encore, ed. cit., pp. 54-55. Sesión del 13/02/1973.

48 Se trata de la célebre crítica kantiana de la psicología y la teología racionales, la crítica del cogito cartesiano y del argumento ontológico que pretenden deducir el ser a partir de un mero concepto -ya sea el del puro pensamiento, ya sea el del ser supremo- sin pasar por la experiencia, única capaz de proporcionar el material para un juicio de existencia.

49 «Es con la lógica como este discurso aprehende lo real, lo reencuentra como imposible, es ella quien lo lleva a su última potencia: ciencia, he dicho, de lo real». J. Lacan, "L'étourdit", en Autres Écrits, Paris, Seuil, 2001, p. 449.

50 J. C. Milner sostiene en su libro L'CEuvre Claire (Paris, Seuil, 1995) que el segundo momento del pensamiento de Lacan, con su abandono progresivo del estructuralismo y de la lógica del significante en beneficio de la exposición de los matemas, supone una renuncia al enfoque trascendental ( $\mathrm{p}$. 122). No obstante, a través de lo que hemos expuesto parece evidente que Lacan no sólo continúa comprometido con el esclarecimiento de las condiciones de posibilidad de la experiencia -que son, en verdad, la imposibilidad, el vacío y lo real-, sino que también adopta una perspectiva crítica que puede parangonarse, casi punto por punto, con las premisas de la dialéctica trascendental kantiana.
} 
hasta aprehender a través de sus fronteras rotas aquello que no puede aprehenderse, aquello que no se sigue ni se deduce sino que irrumpe, el encuentro con la imposibilidad.

\subsection{El mito del enigma de la feminidad: «Da igual. Prueba otra vez. Fracasa otra vez.} Fracasa mejor» ${ }^{51}$

Lo deseable ante este fracaso que es una suerte es que no se lo intente transmutar en triunfo, que se preserve el hueco del fallo -«da igual, prueba otra vez, fracasa otra vez»frente a cualquier falaz "eureka" que quisiera arrogarse el derecho de comprender el misterio de la diferencia y la relación sexual. El misterio que oculta la diferencia es, en verdad, que no hay misterio. La teoría de Lacan, lejos de perseguir el desciframiento de un presunto contenido codificado o velado, trata de poner al descubierto la construcción de la fantasía del contenido; lejos de buscar una verdad escondida, destapa la misma ausencia de verdad y de sentido que las construcciones simbólicas e imaginarias camuflan -la verdad, en todo caso, está ahora del lado de lo real vacío; es, para decirlo con Kristeva, vréel-. El enfoque lacaniano de la diferencia sexual se retrotrae así para denunciarlo al momento en que desde el fracaso y el vacío, quizás por la angustia que produce permanecer instalado allí, se postula con el hilo del lenguaje y la imaginación una plenitud oculta y perdida.

Sostener la existencia de un secreto que permitiría cuadrar y conjugar la diferencia sexual en una relación a menudo conduce a arrojar ese misterio del lado del otro y, en definitiva, a convertir al otro en todo lo que uno no es. La literatura -incluida en ocasiones la psicoanalítica- tradicionalmente ha hecho de la mujer la sede del misterio, la guardiana de esa oscuridad cuyo reverso serían la claridad y evidencia masculinas. Pero también ha habido literaturas que han sabido destapar ese misterio, abrir el Sileno y mostrar su vacío ${ }^{52}$, y en esa línea quisiéramos leer a Lacan.

El hecho de que la mujer sea no-toda, es decir, que no esté toda ella sometida a la función fálica, no confina, como a menudo se ha querido interpretar, una parte de lo femenino a un presunto más allá pre-simbólico - no hace de la mujer una instancia que se hurtaría al modo de ser fenoménico y se expresaría con un lenguaje no-simbólico propio-, sino que indica que en la posición femenina, probablemente por razones históricas, se está más cerca, es más fácil intuir la proximidad de ese vacío sobre el cual vendrán a edificarse las construcciones del símbolo. Sin embargo, la ambigüedad de la frontera entre una presunta cosa en sí substancial y el vacío que se resiste a ser objeto o sujeto ha hecho que se confunda lo uno con lo otro, que se elabore toda una mística de la feminidad y de su particular esencia en detrimento de la revelación del secreto acerca de la ausencia de secreto, en lugar de aprovechar esa vecindad del abismo para dejar al descubierto la condición de «telón sin detrás» de toda identidad sexual.

51 «All of old. Nothing else ever. Ever tried. Ever failed. No matter. Try again. Fail again. Fail better». S. Beckett, "Worstward Ho", en Nohow On, Londres, 1992, p. 101.

52 Como es el caso, por ejemplo, de Marguerite Duras. En El amante, da cuenta de su biografía como sigue: «La historia de mi vida no existe. Eso no existe. Nunca hay dentro. Ni camino, ni línea. Hay vastos espacios donde se ha hecho creer que había alguien, pero no es verdad, no había nadie». M. Duras, L'Amant, Paris, Minuit, 1986, p. 14. Cfr. también M. Duras, Écrire, Paris, Gallimard, 1995, pp. 63-64 y 86: «Escribir. Yo no puedo [...]. Hay que decirlo: no se puede. Y escribimos [...]. No puedo decir nada. No puedo escribir nada». 
Lacan estudia el ideal del amor cortés como uno de los fenómenos en los que con más claridad se ponen de relieve los efectos de la sublimación que afecta a la posición femenina. Por medio de la sublimación, la posición femenina es elevada «a la dignidad de la Cosa como tal» (SVII 20/01/1960), es decir, liberada de la determinación simbólica del concepto. Sin embargo, este vaciamiento es un terreno muy propicio para la construcción de la ficción del misterio, para la confusión del vacío con una Cosa-en-sí substancial y enigmática: el amor cortés ha contribuido, a la vez que hacía visibles sus engranajes, a forjar el mito de la mujer eternamente distante e inalcanzable, a confundir el objeto-causa de deseo con un objeto empírico. La sublimación no es, como aclara Lacan, una realización de la Cosa ${ }^{53}$, sino una aproximación al abismo de la nada sobre el que se tienen precariamente todos los semblantes del ser.

Ya en el seminario de 1959-1960, La ética del psicoanálisis, si bien no alcanza un tono tan crítico como el que adoptará diez años después, la exposición del ingenio del amor cortés busca operar una vuelta de tuerca, busca «en la ilusión algo en lo que la ilusión misma de algún modo se trasciende, se destruye, mostrando que sólo está allí en tanto que significante» ${ }^{54}$ y dejando así al descubierto el vacío. El objeto femenino en la poesía del que se lamenta de su desgracia presupone para afirmarse una barrera que lo rodea y aísla, sólo se introduce por la puerta de la privación y de la inaccesibilidad. Y es esa ubicación de la mujer en el más-allá lo que hace que la Dama sea descrita con caracteres despersonalizados, lo que hace que todos los poemas del amor cortés parezcan dirigirse a la misma persona, a nadie en particular. «El objeto femenino está vaciado de toda substancia real [...].Nunca la Dama es calificada por sus virtudes reales y concretas, por su sabiduría, su prudencia o ni siquiera su pertinencia» 55 . Así, la lectura detenida de este tipo de poesía permite a Lacan inferir que «el ser al que el deseo se dirige no es más que un ser de significante», un objeto inhumano, un ente de razón y no un ser histórico o de carne y hueso ${ }^{56}$. Ahora bien, el problema es que la incidencia del ideal del amor cortés sobre la sociedad-que, como reconoce Lacan, dura hasta nuestros días- no se produjo bajo la forma de una crítica de las identidades, sino que «fue el principio de una moral, de toda una serie de comportamientos, de lealtades, de medidas, de servicios, de ejemplaridad en la conducta» ${ }^{57}$; sobre el vacío de la mujer se proyectó un peso substancial que convirtió la ausencia en un enigma cargado de ontología, en lugar de mantener patente que se trataba de «una organización artificial, artificiosa, del significante» ${ }^{58}$. No es, por tanto, que el punto de partida del amor cortés sea un secreto escon-

53 En respuesta a una pregunta, en la clase del seminario sobre la ética del psicoanálisis del 03/02/1960, Lacan dice lo siguiente: «El esfuerzo de sublimación, dice usted que tiende a la finalidad de realizar la Cosa o a salvarla. Es verdad y no es verdad. Hay allí una ilusión». J. Lacan, Le Séminaire, livre VII. L'éthique de la psychanalyse, Paris, Seuil, 1986, p. 160.

54 J. Lacan, Le Séminaire, livre VII. L'éthique de la psychanalyse, ed. cit., p. 163. Sesión del 10/02/1960. Vid. también pp. 169-170: Cézanne «haciendo manzanas hace algo totalmente diferente de imitar manzanas [...]. Pero, cuanto más presentificado está el objeto en tanto que imitado, más nos abre esa dimensión en la cual la ilusión se quiebra y apunta a otra cosa».

55 J. Lacan, Le Séminaire, livre VII. L'éthique de la psychanalyse, ed. cit., pp. 179 y 180. Sesión del 10/02/1960.

56 Ibidem, p. 254. Sesión del 11/05/1960.

57 Ibidem, p. p. 174. Sesión del 10/02/1960.

58 Ibidem, p. 181. Sesión del 02/03/1960. 
dido, sino que una serie de comportamientos, rituales o manifestaciones produjo a la mujer como secreto.

En el seminario de 1972-1973, Aún, el objetivo de Lacan se concentra en denunciar la «finta» del amor cortés, evidenciar que no es sino «una manera muy refinada de suplir la ausencia de relación sexual fingiendo que somos nosotros los que la obstaculizamos» 59 , que alguno de los implicados en esa no-relación tiene en su poder la capacidad de decidir si la transforma en una relación. El problema del amor cortés es que demasiado rápido convierte el fracaso en un triunfo $-\mathrm{y}$, en todo caso, si el triunfo no se consuma, no pasa de la potencia al acto, es porque yo no quiero, no porque no pueda, al viejo estilo de la zorra y las uvas-, encuentra una vía fácil para "salir airosos" del fallo estructural: «el amor cortés es para el hombre, cuya dama era enteramente, en el sentido más servil, su súbdita, la única manera de salir airoso de la ausencia de relación sexual» 60 .

El presupuesto que sostiene la mentalidad del amor cortés es que si hay un goce que no se alcanza, es porque el objeto amado, la mujer, se parapeta detrás de una barrera; pero el caso es que lo hay. Frente a esto, Lacan tratará de demostrar que lo que acontece es más bien lo contrario: falta un goce, el goce pleno, el goce de la totalidad, y falta porque hay palabras; ahora bien, «el goce que falta debe traducirse el goce que hace falta que no haya» 61 , es decir, es necesario que no lo haya, no puede haberlo, y cualquier principio que presuma su existencia será fraudulento -no hay negocio redondo-. Que la mujer se dé no-toda, que no todo de ella se dé, no equivale inmediatamente a que lo que impugna la totalidad permanezca oculto o agazapado pero siempre siendo ya algo. Con Valéry, ante la pregunta «¿Qué soy?», Lacan responde: «soy en el lugar desde donde se vocifera que "el universo es un defecto en la pureza del No Ser"» ${ }^{62}$. El universo, lo universal, la totalidad, es defecto, défaut, falta. Y así debe ser. En este "debe ser", o más bien este "debe no ser", "debe no haberlo" (Il ne faut pas), radica el imperativo crítico de Lacan que va a proteger a "lo femenino" de toda caracterización substancial, pues si no lo hay y no puede haberlo -si no hay totalidad, goce pleno-, entonces la mujer no puede ser la depositaria del misterio que, por tanto, tampoco hay. Pero, a la vez, lo femenino recoge el testigo de la no-relación sexual para asumir la condición de punto de fuga o falla que impide el cierre y la clausura, es decir, la propia posición femenina entrañará ya, una vez se la haya despojado de las atribuciones simbólicas e imaginarias, un modo de ser crítico, una denuncia del esencialismo a través de la inconsistencia.

\section{La dialéctica trascendental de la relación sexual}

Me envías al vacío para que allí acreciente yo mi arte y mi poder. Me tratas de esta suerte para que, como el gato de la fábula, yo te saque las castañas del fuego. Pero ¡adelante siempre! Profundicemos la cosa; en tu Nada espero encontrar el Todo.

J. W. Goethe, Fausto

\footnotetext{
59 J. Lacan, Le Séminaire, livre XX. Encore, ed. cit., p. 65. Sesión del 20/02/1973.

60 Idem.

61 Ibidem, p. 55. Sesión del 13/02/1973.

62 J. Lacan, "Subversion du sujet et dialectique du désir", en Écrits, ed. cit., p. 819.
} 
Si el tratamiento lacaniano de la relación sexual se puede leer como una operación crítica que tendría las características de una dialéctica trascendental -análisis de la lógica de la ilusión-, es porque, de entrada, ese goce que hace falta que no haya, esa plenitud o totalidad, es algo parecido a una idea de la razón, y donde dice "razón" Lacan entenderá "inconsciente" - de ahí que titulara su artículo "La instancia de la letra en el inconsciente o la razón desde Freud"-. El ser humano no puede despojarse de la idea de totalidad - «la ilusión trascendental no cesa [...], aunque haya sido ya descubierta y se haya comprendido claramente su nulidad» ${ }^{63}$-, pero tampoco puede proporcionar un correlato objetivo para ella sin echar mano de la fantasía, de una cierta «lógica de la ilusión»64; de ahí que tanto Kant como Lacan subrayen la necesidad de una crítica que denuncie el uso ilegítimo - es decir, con pretensiones objetivas- de las ideas de la razón, una crítica que pese a la inevitabilidad del problema ponga cotas a sus aspiraciones. En este sentido, «la dialéctica trascendental se conformará [...] con detectar la ilusión de los juicios trascendentes y con evitar, a la vez, que nos engañe. Nunca podrá lograr que desaparezca incluso (como la ilusión lógica) y deje de ser ilusión. En efecto, nos las habemos con una ilusión natural e inevitable, que se apoya, a su vez, en principios subjetivos haciéndolos pasar por objetivos» ${ }^{65}$.

Como es bien sabido, Kant catalogó las ideas trascendentales en tanto que conceptos de la razón que piensan un totum 66 en tres clases: la primera, Yo, abordaría la unidad absoluta -incondicionada- del sujeto pensante; la segunda, Mundo, la unidad absoluta de las condiciones del fenómeno, el conjunto de todos los fenómenos; la tercera, Dios, la unidad absoluta de la condición de todos los objetos del pensamiento en general, aquello que encierra la suprema condición de posibilidad de todo lo pensable o, lo que es lo mismo, el ser de todos los seres 67 . La ilusión se genera cuando se dota de entidad objetiva al referente ausente de estas ideas y se las utiliza como argumentos de silogismos que, desde ese momento, no podrán ser sino dialécticos ellos también. Así, del concepto trascendental del sujeto se infiere -por medio de lo que Kant llama un paralogismo- su unidad absoluta; la segunda inferencia dialéctica -que conduce a la situación de antinomia- obtiene un concepto trascendental de la absoluta totalidad de la serie de condiciones relativas a un fenómeno dado en general; y, por último, se infiere de la totalidad de las condiciones requeridas para pensar objetos en general -es decir, de las cosas que no se conocen por su mero concepto trascendental- la absoluta unidad sintética de todas las condiciones de posibilidad de las cosas en general, esto es, un ser de todos los seres -y a esta inferencia Kant la denominará "ideal de la razón pura"-68.

El silogismo que lleva de la existencia de lo condicionado a la suposición de lo incondicionado es el vehículo que utilizan las ideas para volar por encima de la experiencia y totalizar, compendiar y convertir en complementarios lo que en realidad no son sino frag-

\footnotetext{
63 I. Kant, Kritik der reinen Vernunft, A 297/B 353. Seguimos la traducción de P. Ribas en la edición de Alfaguara (Madrid, 1978).

64 Ibidem, A 293/B 349.

65 Ibidem, A 297/B 354.

66 E. Fink, Todo y nada. Una introducción a la filosofía, trad. N. Á. Espinosa, Buenos Aires, Editorial Sudamericana, 1964, p. 101.

67 I. Kant, Kritik der reinen Vernunft, A 334/B 391.

68 Ibidem, A 340/B 398.
} 
mentos parciales. Ahora bien, cuando esa totalidad deja de concebirse como una pura idea de la razón -que en sí misma haría de directriz regulativa en la actividad del conocimiento 69 - y se toma por un objeto real, cuando se hace una interpretación ontológica de esa totalidad, se produce un salto ilegítimo que hipostasía lo que en verdad sólo existe en el pensamiento. «Aunque el ideal del ens realissimum no sea más que una simple representación, se comienza por realizarlo, es decir, por convertirlo en objeto; después es hipostasiado; finalmente se da un paso más, natural en la razón con vistas a la unidad completa, y es incluso personificado» 70 .

La crítica de la razón pura descubre en esa totalidad que se quiere objetiva una fantasmagoría, una «mera ficción»71, una «teología especulativa con puros pensamientos vacíos» 72. Kant introduce una «singular transformación», como la llamó Eugen Fink, en el tratamiento del problema de la totalidad: la ilusión trascendental por excelencia concierne al anhelo de totalidad -el mismo que ambiciona un lenguaje que pueda decirlo todo y que pueda decir todo el sentido que quiere decir, ni más ni menos, un lenguaje al que no le haga falta decir «esto es todo» para decirlo todo; el mismo anhelo, también, que delira una complementariedad entre los sexos, una suma que daría como resultado una totalidad-, pero resulta imposible proporcionar referente objetivo alguno de ese anhelo, de modo que «el "todo" se convierte en un pensamiento que no se refiere a "nada"»y, más aún, que es en sí mismo la nada ${ }^{73}$. «Esta ontología negativa de la totalidad es la verdadera contribución de su crítica» 74 .

El "No" de Lacan se emparenta con esta singular transformación; en el "Sí" y en los triunfos pervivirían las formas teológicas del pensamiento de la totalidad. Trasladando el funcionamiento de las tres inferencias dialécticas al terreno de la no-relación sexual, lo que el psicoanálisis permitiría destapar es, en primer lugar, la falaz unidad que cada uno de los sujetos que aspiran a entrar en relación reivindica para su pareja y para sí -unidad que vendría a traducirse en una serie de características esenciales y positivas: la hipóstasis del otro y el recurso a una diferencia sexual preexistente y cuasi-natural tendrían así como finalidad proveer de una garantía que asegure una identidad para cada sexo frente a la amenaza de precariedad e incluso imposibilidad-; en segundo lugar, la inexistente e imposible totalidad que la creencia en la relación sexual y en el goce pleno habría señalado como su objetivo ${ }^{75}$;

69 «[...] la razón, al basar en ella [la idea trascendental] la completa determinación de las cosas en general, únicamente la tomó como concepto de toda la realidad, sin exigir que toda esta realidad estuviese dada objetivamente ni constituyera, a su vez, una cosa». Ibidem, A 580/B 608.

70 Ibidem, A 583 / B 611.

71 Ibidem, A 580/B 608.

72 E. Fink, Op. cit., p. 102.

73 Ibidem, p. 103. Cfr, p. 112: «No debemos decir sólo que tales pensamientos, tales conceptos racionales se refieren a la nada: ellos son en sí mismos la nada».

74 Ibidem, p. 118.

75 «El mundo, a Dios gracias, el mundo está en descomposición. El mundo vemos que ya no se sostiene, pues aun en el discurso científico está claro que de él no hay el menor atisbo. A partir del momento en que se puede agregar a los átomos una cosa que se llame el quark, y que éste es el verdadero hilo del discurso científico, tendrán que reconocer a la postre que se trata de otra cosa y no de un mundo». J. Lacan, Le Séminaire, livre XX. Encore, ed. cit., p. 37. Sesión del 09/01/1973. 
y, en tercer lugar, la transformación del objeto de deseo en una suerte de ser supremo que contendría la respuesta incondicionada a todos los misterios y enigmas de la sexuación. De este modo, siguiendo a Kant, Lacan no sólo habría des-esencializado la ontología de las identidades sexuales, sino que además habría purgado de ella la pregunta teológica por el ente en su totalidad 76 .

En consecuencia, lo que hay no es relación sexual sino división por doquier, dentro del propio sujeto y entre los sujetos sexuados; desde que "el todo" no existe, lo que hay es ruptura o distancia sin reconciliación, división como instancia última77. Queda así una realidad porosa y taladrada cuyos agujeros la razón trata de tapar ilusoriamente. Y, además, esa oquedad que afecta a todo lo que hay es la que impide que la división se utilice como un procedimiento lógico que agotaría la totalidad, impide que la dihairesis sirva para algo más que dividir, para trazar un sistema cerrado. El hecho de que cada ser humano haya de inscribirse en una de las posiciones de la sexuación, el hecho más banal de que hayamos siempre de elegir una u otra puerta en los aseos, no hace ni mucho menos que el silogismo disyuntivo agote la totalidad. $\mathrm{Si}(A v B)$ constituye un todo, es en cualquier caso un todo fallido. En este sentido, pretender que hay goce pleno equivaldría a postular un Dios que rellenase los hue$\cos ^{78}$, postular que los huecos pueden ser rellenados. Ahora bien, la esperanza que suscita esa pretensión cobra la forma de una espera a Godot, un Godot que nunca llega pero que tampoco es un ser u objeto que fue poseído en un momento determinado, perdido después y que ahora se busca nostálgicamente. «Beckett [...] lo ha llamado un día Godot, ¿por qué no haberlo llamado por su verdadero nombre, el Ser supremo?» 79 . Desde estas premisas, Lacan concluye que los dos personajes que esperan a Godot son, pese a ser dos, impares, sin par, imposibles de com-parar 80 .

Cuando Lacan tacha la $A$ y niega que haya Otro del Otro o garantía, cuando tacha también el $L a$ de "La mujer" y afirma la imposibilidad de la relación sexual, lo que está haciendo es reivindicar el espacio vacío y declarar ilegítima cualquier saturación de éste. El tratamiento que Kant hace del problema de la totalidad deja al descubierto que el concepto del totum es «un enmascaramiento de la nada» 81 , y esa misma línea es la que sigue Lacan en su lista de noes. La función del lenguaje una vez aplicada la crítica no es, por ende, la de «tapar un agujero, éste constituido por la no-relación, la no-relación constitutiva de lo sexual, pues esa no-relación no depende sino de él. El lenguaje no es por tanto simplemente un tapón, es aquello en lo que se inscribe esa no-relación» 82 . Y aquello en lo que se inscribe la no-rela-

76 E. Fink, Op. cit., p. 124: «La teología dentro de la metafísica es la forma como se pregunta por el ente en su totalidad».

77 F. Martínez Marzoa, "Kant y la mota de polvo", en Lógos. Anales del seminario de metafísica, Madrid, Universidad Complutense de Madrid, vol. 37, 2004, p. 59.

78 J. Lacan, Le Séminaire, livre XX. Encore, ed. cit., p. 100. Sesión del 08/05/1973.

79 J. Lacan, Le Séminaire, livre IX. L'identification, ed. cit., sesión del 13/06/1962.

80 «[...] el número dos se regocija de ser impar (y tiene mucha razón el número dos de regocijarse de serlo, pero tiene el defecto de no ser como para decir por qué) - encontrará en el nivel del inconsciente su más significante alcance, purificado de sus equívocos, si se lo traduce por: unos números, son dos, que no tienen par, esperan a Godot». J. Lacan, "Situtation de la psychanalyse en 1956", en Écrits, ed. cit., pp. 471-472.

${ }^{81}$ E. Fink, Op. cit., p. 114.

82 J. Lacan, Le Séminaire, livre XXII. R.S.I., ed. cit., sesión del 17/12/1974. 
ción es algo muy diferente de lo que viene a tapar o a dar contenido a lo que de suyo es el conjunto vacío.

No es casual que Kant eligiera retratar el territorio de los noúmenos «como un espacio vacío» 83 y la distancia que nos separa de ellos como un abismo (Kluft); un abismo, además, que no debe ser llenado: «En efecto, nadie puede ni debe determinar cuál es el supremo grado en el cual tiene que detenerse la humanidad, ni, por tanto, cuál es la distancia que necesariamente separa la idea y su realización» ${ }^{84}$. Si bien en la naturaleza no se dan saltos ni hiatos, si bien no hay jamás laguna o grieta (Kluft) alguna entre dos fenómenos en el conjunto de las intuiciones en el espacio ${ }^{85}$, cuando se trata de las ideas y la experiencia hay una dislocación estructural, una inadecuación que es la peculiaridad esencial de la idea. Ciertamente, en la medida en que el fenómeno se inscribe sobre el vacío, este vacío queda registrado en el fenómeno como su límite. Y de manera paradójica, ese afuera que ejerce de antídoto contra cualquier clausura o consistencia es a la vez lo que permite a lo de dentro convertirse en conjunto. El «gran secreto del psicoanálisis» 86 -la sucesión de noes- es, por su parte, una reformulación de la prohibición kantiana de llenar el espacio vacío.

El Godot que nunca llega -la totalidad/Dios- no es más el fundamento trascendente prometido sino una idea producida por la propia razón, no es causa sino efecto y habrá de mantenerse su «esterilidad óntica» -no podrá hacer válido nada, no podrá fundamentar ${ }^{87}$. Así, no es ya que la razón esté incluida en una totalidad mayor, sino que es la totalidad la que sólo es en la razón, bajo la forma de idea: «la razón finita no está en el mundo ni bajo Dios, sino mundo y Dios son "en ella"; la razón humana "tiene" en sí las ideas de la totalidad; el más finito de los entes está inquieto, azorado, fuera de toda auténtica seguridad, asustado por las ideas de la totalidad cósmica y supracósmica que habitan en él» ${ }^{88}$. Lo que Felipe Martínez Marzoa dice de Kant es el nervio mismo que alienta los tachados lacanianos: «Es esencial al pensar de Kant el que para la empiricidad de los contenidos no hay, por así decir,

83 I. Kant, Kritik der reinen Vernunft, A 260/B 315: «El concepto de objetos puros, meramente inteligibles, carece por completo de principios relativos a su aplicación, ya que no somos capaces de imaginar cómo tendrían que darse. Aunque el pensamiento problemático deja sitio para tales objetos, sólo sirve, como un espacio vacío, para limitar los principios empíricos, pero sin contener en sí ni revelar otro objeto de conocimiento fuera de la esfera de esos principios». Cfr. también A 255/B 310: «Lo que está fuera del campo de los fenómenos es (para nosotros) vacío».

84 Ibidem, A 317/B 374. Cfr. I. Kant, Kritik der praktischen Vernunft, AA V: 55: «Para la especulación no haríamos nosotros, aunque lo lográsemos, ninguna verdadera adquisición en el conocimiento de la naturaleza, y, en general, en consideración de los objetos que nos puedan ser dados de algún modo, sino que en todo caso daríamos un paso más allá de lo sensiblemente condicionado (permanecer en él y caminar con celo por la cadena de las causas nos da ya bastante que hacer) a lo suprasensible, para completar y limitar nuestro conocimiento por el lado de los fundamentos, aunque quedaría sin llenar siempre un abismo [Kluft] infinito entre aquellos límites y lo que nosotros conocemos, y habríamos prestado oídos más bien a una vana curiosidad que a un deseo profundo de saber». Seguimos la traducción de E. Miñana y Villagrasa y M. García Morente en la edición de Sígueme (Salamanca, 1994). 85 I. Kant, Kritik der reinen Vernunft, A 229/B 281.

86 J. Lacan, Le Séminaire, livre VI. Le désir et son interprétation, versión inédita de la Association Freudienne Internationale, sesión del 08/04/1959.

87 F. Martínez Marzoa, "Kant y la mota de polvo", p. 62.

88 E. Fink, Op. cit., p. 104 (la cursiva es nuestra). 
salvación, entendiendo por tal algún expediente que, aun cuando fuese sólo metadiscursivamente, remitiese de la certeza de facto (que obviamente comporta incertidumbre) a algún de iure o in re que comportase certitudo» ${ }^{89}$. Y es que lo que proporcionaría la salvación de la certeza contingente es esa totalidad que en Lacan se llama el Otro del Otro.

La crítica asume como misión mantener a raya al concepto de totalidad que por una «inclinación fatal» 90 aplicamos de un modo no crítico al alma, al mundo y a Dios. Y en ese gesto, como ya hemos visto, hace patente una imbricación íntima entre el totum y el nihil, explicita la confusión recíproca entre ellos, destapa la nada que subyace. Ahora bien, que nos relacionemos con la nada bajo la máscara del todo no significa que estemos haciendo nada, sino que de esa relación se siguen una serie de consecuencias ${ }^{91}$; como en el amor cortés, se generan una serie de comportamientos, rituales, etc., se organiza una determinada pauta de acción y de posicionamiento frente a los hechos, lo cual en modo alguno es inocuo. Además, en tanto que trascendental, la representación de la totalidad es algo a lo que la razón no puede renunciar por mucho que se explicite su carácter engañoso; sin embargo, como en Kant, también existe un uso regulativo de esta representación en el que, despojada de todo marchamo onto-teológico, cumple una función fundamental. Desde luego, así como la relación sexual o la mujer, lo universal de la totalidad pertenece al terreno del "no" o del fracaso: cualquier determinación de un principio universal llevará adherida a sus premisas esa falla. Pero del mismo modo que el lenguaje fracasa constantemente -siempre dice demasiado o demasiado poco-, pese a lo cual -y por lo cual- tenemos la imperiosa necesidad de seguir hablando, la relación sexual, la subjetividad y la universalidad no cesan de fracasar, aunque la inevitabilidad de que salten a la palestra de los problemas que acucian al ser humano invita a que, ya que fracasamos, al menos tratemos con Beckett de fracasar mejor -y en este caso, fracasar mejor quiere decir hacer uso de lo universal sin hipostasiarlo, substancializarlo, personalizarlo 92

\author{
Emma Ingala Gómez \\ Departamento de Filosofía Teorética \\ Universidad Complutense de Madrid \\ eaingala@filos.ucm.es
}

\footnotetext{
89 F. Martínez Marzoa, "Kant y la mota de polvo", p. 60.

90 E. Fink, Op. cit., p. 100.

91 Ibidem, p. 115: «El "totum" y el "nihil" se imbrican de un modo notable. Cuando creemos relacionarnos racionalmente con las tres formas de la totalidad, con la substancia anímica, con el cosmos y con Dios, nos relacionamos, en verdad, según lo que informa la "filosofía crítica" de Kant, con la nada. Pero tales relaciones con la nada son por su parte no nada, en tanto actitudes del pensar».

92 Excede el propósito de este trabajo analizar, también en paralelo con Kant, el modo en que la totalidad se recupera no ya en el uso teórico sino en el uso práctico de la razón. Remitimos de momento para ello a los siguientes artículos de Ernesto Laclau: "Universalism, Particularism and the Question of Identity", en October, vol. 61, The Identity in Question, Summer, 1992; "Ideology and Postmarxism", in Journal of Political Ideologies, 11 (2), June 2006, pp. 103-114.
} 